\title{
TG09
}

\section{On the Development and Stimulation of Tight} Gas Reservoirs

\author{
W. El-Rabaa* (ExxonMobil Upstream Reseach Company)
}

\section{SUMMARY}

Development of tight gas reservoirs is an integrated effort between many disciplines, including geoscience and subsurface engineering. In all tight gas reservoirs, effective stimulation is one of the key factors for economic gain.

Globally, ExxonMobil has developed many tight gas reservoirs with matrix compositions ranging from sandstones, shales and carbonates. Various well geometries, combined with diverse artificial stimulation techniques are used to increase well productivity resulting in improved economics.

This paper will present a road map of reservoir-based selection criteria which will result in a suitable stimulated wellbore configured to optimize gas recovery from tight reservoirs. ExxonMobil tight gas field examples are also presented. 